(2) Open Access Full Text Article

REVIEW

\title{
Sumatriptan-naproxen fixed combination for acute treatment of migraine: a critical appraisal
}

This article was published in the following Dove Press journal:

Drug Design, Development and Therapy

22 January 2010

Number of times this article has been viewed

\section{Chaouki K Khoury \\ James R Couch}

Department of Neurology, University of Oklahoma Health Sciences Center, Oklahoma City, Oklahoma, USA
Correspondence: Chaouki Khoury Department of Neurology, 7 I I Stanton L. Young Blvd, Ste 215, Oklahoma City, Oklahoma 73I04, USA

$\mathrm{Tel}+$ I 405 27I 4 III3

Fax + 405 27| 5723

Email chaouki-khoury@ouhsc.edu

\begin{abstract}
Nonsteroidal anti-inflammatory drugs (NSAIDs), including naproxen and naproxen sodium, are effective yet nonspecific analgesic and anti-inflammatory drugs, which work for a variety of pain and inflammatory syndromes, including migraine. In migraine, their analgesic effect helps relieve the headache, while their anti-inflammatory effect decreases the neurogenic inflammation in the trigeminal ganglion. This is the hypothesized mechanism by which they prevent the development of central sensitization. Triptans, including sumatriptan, work early in the migraine process at the trigeminovascular unit as agonists of the serotonin receptors (5-HT receptors) 1B and 1D. They block vasoconstriction and block transmission of signals to the trigeminal nucleus and thus prevent peripheral sensitization. Therefore, combining these two drugs is an attractive modality for the abortive treatment of migraine. Sumatriptan-naproxen fixed combination tablet (Treximet $^{\mathbb{R}}$ [sumatriptan-naproxen]) proves to be an effective and well tolerated drug that combines these two mechanisms; yet is far from being the ultimate in migraine abortive therapy, and further research remains essential.
\end{abstract}

Keywords: Treximet $^{\mathbb{B}}$, sumatriptan-naproxen, migraine, treatment

\section{Introduction to management of acute migraine}

The lifetime prevalence of headache is over $90 \% .{ }^{1}$ Tension type headache is the most common of the primary headache disorders, with a prevalence of $42 \%$ to $78 \%{ }^{1,2}$ Migraines on the other hand occur at a frequency of $18 \%$ to $33 \%$ in females vs $7 \%$ to $13 \%$ males. $^{3,4}$ It is estimated however that over half of migraineurs remain undiagnosed $!^{5}$

The burden of migraine is not negligible. Around a quarter of migraineurs lose 6 or more days of work per year, ${ }^{6}$ resulting in $\$ 300$ to $\$ 570$ per month of lost labor per patient $^{7}$ and over $\$ 1,600$ per year in individual medical cost. ${ }^{8}$ This amounts to a total

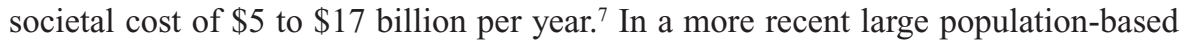
study, 2/3 of migraineurs experienced one or more attacks every month. ${ }^{9}$ Nonetheless, until recently, research in migraine management has lagged behind other fields of medicine.

In formulating a treatment strategy for migraine, it is recommended that the approach be multidimensional, including: $:^{10}$ a) Nonpharmacologic approaches and physical techniques, such as behavioral medicine techniques, manipulation, acupuncture, and physical therapy; b) Abortive therapy; c) Prophylactic therapy; d) Adjunctive therapies in migraine (vitamins, minerals, supplements, herbs), eg, vitamin B-2, Mg, feverfew, petasites, melatonin, coenzyme Q10.

submit your manuscript | www.dovepress.com 
A recent guideline published by the European Federation of Neurologic Societies (EFNS) ${ }^{11}$ lists the following symptomatic treatments for individual headache attacks or abortive therapy (organized between specific and nonspecific treatments):

a) nonspecific therapy with medications that relieve pain, including: i) NSAIDs: aspirin, ibuprofen, naproxen, diclofenac, paracetamol, other NSAIDs and NSAIDs combined with nonNSAID analgesics, ii) nonnarcotic pain medication: caffeine, tramadol; iii) narcotics, noting that these are only of minor efficacy; iv) antiemetics: metoclopramide, domperidon; v) corticosteroids; vi) intravenous valproate; vii) semi-specific medications: isomethoptene, butalbital (not in the EFNS guideline).

b) specific abortive medications: i) triptans, ii) ergot derivatives: ergotamine, dihydroergotamine (DHE).

Prophylactic anti-migraine therapy (PAMT) includes a multitude of agents with varying degrees of data to support them: a) agents with a level A recommendation: i) certain beta-adrenergic blockers (metoprolol, propranolol); ii) flunarizine, certain anticonvulsants (topiramate, valproate). b) agents with less supportive data: i) tricyclic antidepressants, especially amitriptyline; ii) NSAIDs (naproxen, aspirin); iii) petasites; iv) other betaadrenergic blockers (bisoprolol); v) other anticonvulsants (gabapentin), neutraceuticals: magnesium, feverfew (Tenacetum parthenium), riboflavin, coenzyme Q10, vi) angiotensin converting enzyme (ACE) inhibitors (lisinopril) and angiotensin-receptor blockers (ARB) (candasar$\tan$ ), vii) methysergide, viii) calcium-channel blockers other than flunarizine, ix) other antidepressants, especially serotonin-norepinephrine reuptake inhibitors (SNRI) (such as venlafaxine), $\mathrm{x}$ ) botulinum toxin $\mathrm{A}$, possibly in chronic migraineurs naïve to other prophylactic treatments.

A holistic approach is therefore advantageous, as the combination of different treatments may be synergistic, especially if combining therapeutic categories. This also allows the addressing of migraine comorbidities.

The role of prophylaxis is to decrease the burden of headache by decreasing the frequency and severity of the headache. Prophylaxis may also enhance the efficacy of abortive therapies. In choosing a prophylactic medication, one should assess the burden of disability from migraine, assess triggers (sleep, diet, or hormones), set reasonable expectations, and respect patient tolerance in terms of speed of action of the medicine versus the tolerance of side effects.
There are no clear guidelines for recommending prophylactic treatment. This is a multidimensional assessment, and considerations include: a) More than 2 attacks a month; b) Inadequate relief from or contraindication to abortive treatment; c) Prolonged, poorly responsive menstrual migraine; d) Degree of disability due to migraine.

Once prophylactic medications are started, the treating physician should monitor the patient for side effects, and reassess efficacy, keeping in mind that it often takes more than 6 weeks for efficacy to be perceived.

Abortive therapy should be individually tailored, taking into consideration the medication class, route of administration, dosing, contraindications, development of tachyphylaxis, and side effects. Effectiveness may vary from subject to subject. Maximum tolerated doses should be tried before concluding a drug is ineffective. Often abortive treatments may need to be varied over time, as some patients appear to develop tachyphylaxis.

\section{Overview of mode of action of sumatriptan-naproxen}

Since migraine has multiple pathogenic mechanisms at play, using combination therapy is an attractive modality. The combination tablet contains $85 \mathrm{mg}$ sumatriptan and $500 \mathrm{mg}$ naproxen. ${ }^{12}$

Naproxen is a NSAID that is available in the US either as a propionic acid (naproxen) or its sodium salt (naproxen sodium). $200 \mathrm{mg}$ naproxen base is equivalent to $220 \mathrm{mg}$ naproxen sodium. ${ }^{13,14}$ It possesses analgesic, anti-inflammatory and antipyretic properties by decreasing the formation of prostaglandin precursors. This is mediated through reversible inhibition of the cyclooxygenase- 1 and 2 (COX-1 and 2) enzymes. Its desired effects are thought to be mediated through the inhibition of COX-2 while its undesirable side effects are mediated through inhibition of COX-1. ${ }^{15-20}$ It is labeled for use in the management of arthritis (ankylosing spondylitis, osteoarthritis, rheumatoid disorders, and gout), mild-to-moderate pain, tendonitis, bursitis, dysmenorrhea, fever, and for the management of dental pain and swelling. ${ }^{13,21-26}$ The use of naproxen in migraine is based on its recommended use for the treatment of mild to moderate pain. It is therefore a nonspecific symptomatic treatment in migraine which remains an unlabeled use in the United States. The recommended initial dosing in migraine therapy is $500-750 \mathrm{mg}$, with additional doses of 250-500 $\mathrm{mg}$ given as needed up to a maximum daily dose of $1250 \mathrm{mg}$. Enteric-coated formulations of naproxen are not recommended for the treatment of acute 
migraine attacks. ${ }^{27-29}$ Naproxen and naproxen-sodium have been tested for migraine prophylaxis with modest results. $^{30}$

Sumatriptan was the first approved antimigraine agent in the United States by the Food and Drug administration (FDA) in 1991. It was initially thought to act as an agonist at the $5-\mathrm{HT}_{1 \mathrm{~B}}$ receptor causing vasoconstriction and pain relief. However, no temporal correlation was identified between the vasoconstriction and pain relief, so other receptors were sought. These were shown to be the $5-\mathrm{HT}_{1 \mathrm{D}}$ receptors, which are densely localized in humans on tissues known to be involved in the pathogenesis of migraine, such as the carotid artery, the circle of Willis, and meninges. They co-localize to nerve endings that also show immunoreactivity to the calcitonin gene related peptide (CGRP) and tyrosine hydroxylase, implicating them in the inhibition of neurogenic inflammation. ${ }^{31}$ Therefore, triptans are now known to be selective $5-\mathrm{HT}_{1 \mathrm{~B}, 1 \mathrm{D}}$ receptor agonists. Both the $5-\mathrm{HT}_{1 \mathrm{~B}}$ and $5-\mathrm{HT}_{1 \mathrm{D}}$ receptors belong to the $5-\mathrm{HT}_{1 \mathrm{D}}$ receptor subfamily and are expressed in the trigeminal ganglion, substantia nigra and basal ganglia, where triptans exert their central effect, regulating the firing rate of dopaminergic neurons. Peripherally, $5-\mathrm{HT}_{1 \mathrm{~B}}$ receptor is expressed on cranial blood vessels and mediates vasoconstriction while the $5-\mathrm{HT}_{1 \mathrm{D}}$ receptor is expressed on trigeminal nerve endings. There, it functions as an autoreceptor, inhibiting serotonin release and decreasing neurogenic inflammation. ${ }^{32}$

Triptans are preferred to ergotamine and ergotamine derivatives, because they are at least as potent, with better tolerability and fewer side effects. While triptans are direct agonists at the 5-HT $\mathrm{HB}_{1 \mathrm{D}, 1 \mathrm{D}}$ receptors, ergotamine has nonspecific partial activity at the tryptaminergic, dopaminergic, and alpha-adrenergic receptors. This leads to vasoconstriction both peripherally and intracranially as well as depression of the central vasomotor centers, which accounts for their increased risk of peripheral vascular, cardiovascular, and cerebrovascular complications. ${ }^{33}$

The advantage of triptans over other analgesics is the fact that triptans not only control pain, but also the nonheadache symptoms of migraine, such as nausea, vomiting, photophobia and phonophobia. ${ }^{34,35}$

Sumatriptan may exert a positive effect in diminishing the migraine any time during the headache in some patients. In others it works primarily if given early in the headache, but not in the aura or prodrome period. Burstein and Jakubowski developed an animal model for neurogenic inflammation in the mouse, by bathing the dura with an "inflammatory soup", the contents of which approximated the extracellular fluid produced at the dura by stimulating the trigeminal ganglion. They demonstrated that in animals exposed to inflammatory soup, there was sensitization at the trigeminal ganglion cells within 20 minutes of exposure. Sumatriptan given before 20 minutes blocked this response. Sumatriptan given after 20 minutes was ineffective. ${ }^{36}$ In a small patient sample, Burstein, Collins and Jakubowski showed that two-thirds of subjects responded to sumatriptan given early in the headache, but not after 20-30 minutes and one-third responded anytime. Ketorolac in their experiment helped prevent sensitization at the trigeminal nucleus neurons. ${ }^{37}$ This helped to provide a background rationale for the use of a combination triptan-NSAID.

\section{Overview of pharmacology of sumatriptan-naproxen}

Sumatriptan-naproxen has a similar side effect profile to sumatriptan. ${ }^{38}$ Administration recommendation is similar to sumatriptan tablets, and despite the fact that it contains naproxen there is no recommendation to take it with food. ${ }^{12}$ Naproxen should be taken with food, milk or antacids as it may cause GI irritation (dyspepsia, bleeding, ulceration, perforation). ${ }^{39}$ Food does not appreciably affect oral bioavailability of sumatriptan (but prolongs time to peak concentration). ${ }^{34,40-43}$

Sumatriptan-naproxen contraindications, precautions, monitoring, pregnancy risk factor and breastfeeding recommendation are otherwise the same as that of its individual components. $^{12}$

Naproxen is contraindicated in: a) Patients with renal insufficiency, when the creatinine clearance is $<30 \mathrm{~mL} /$ minute; ${ }^{13}$ b) Treatment of the perioperative pain of coronary artery bypass graft (CABG) surgery; $\left.{ }^{44} \mathrm{c}\right)$ Aspirin-sensitive asthma; ${ }^{13}$ with note that polymorphism in the leukotriene C(4) synthase promoter region (A444C) may contribute to the asthma reaction seen with NSAIDs use ${ }^{45,46} \mathrm{~d}$ ) Patients with known hypersensitivity to aspirin or NSAIDs, or any component of the formulation. ${ }^{13}$

Naproxen should also be used with caution in patients with the following problems: a) Known cardiovascular disease or cardiovascular risk factors; ${ }^{13}$ b) Heart failure, as it may increase the risk of fluid accumulation and edema; ${ }^{13,47}$ c) Hypertension; ${ }^{13,47}$ d) On low-dose aspirin for antiplatelet therapy, as coadministration of naproxen and aspirin interferes with aspirin's antiplatelet effect; therefore naproxen should be administered 2-8 hours or more before aspirin or 30-120 minutes after aspirin; ${ }^{13,48,51}$ e) History of 
gastrointestinal (GI) disease, especially peptic ulcer disease or GI bleeding; ${ }^{13,52} \mathrm{f}$ ) Renal insufficiency, with creatinine clearance still $>30 \mathrm{~mL} /$ minute; $;^{13,53} \mathrm{~g}$ ) Undergoing major surgery, as they interfere with platelet aggregation and increase the risk of bleeding; therefore, naproxen should be withheld for 3-5 half-lives prior to surgery; $;^{13,14} \mathrm{~h}$ ) Asthma other than aspirin-sensitive asthma, as they may also have aspirin-sensitive asthma; ${ }^{13}$ i) Hepatic impairment; ${ }^{13,14}$ j) On medication with risk of agranulocytosis, such as clozapine and carbamazepine, as naproxen may rarely cause agranulocytosis; ${ }^{5,46} \mathrm{k}$ ) On lithium therapy, as naproxen may increase serum lithium levels, with a potential for lithium toxicity. ${ }^{13,14}$

Sumatriptan is contraindicated in patients with: ${ }^{40,54,55}$ a) Known hypersensitivity to sumatriptan or any component of the formulation; b) Ischemic heart disease or signs or symptoms of ischemic heart disease; c) Cerebrovascular disease; d) Peripheral vascular syndromes; e) Uncontrolled hypertension; f) Prior use of ergotamine, ergotamine derivatives or another 5-HT 1 agonist within the preceding 24-hour period; g) Prior (within 2 weeks) or current usage of MAO inhibitor; h) Hemiplegic or basilar migraine; i) Severe hepatic impairment.

Therefore, patients on sumatriptan-naproxen, because of the naproxen component, should be monitored for occult blood loss and for their urine output. In addition, periodic monitoring of liver function tests, complete blood counts $(\mathrm{CBC})$, blood urea nitrogen (BUN) and serum creatinine should also be performed. ${ }^{13,14,56}$

Due to a theoretical concern for increased incidence of serotonin syndrome, ${ }^{41,57-59}$ caution should be exercised when using sumatriptan-naproxen, sumatriptan alone, or any other triptan in patients with seizure disorders or with a lowered seizure threshold, as well as in patients who are on a selective serotonin reuptake inhibitor (SSRI) or SNRI. This theoretical risk seems however to be unwarranted, since the pathophysiology of the serotonin syndrome involves activation of 5- $\mathrm{HT}_{1 \mathrm{~A}}$ and 5- $\mathrm{HT}_{2 \mathrm{~A}}$ receptors, not the receptors to which triptans are agonist. ${ }^{60}$ Several reports also point to fact that this does not happen in clinical practice. Even when combining a triptan with a SSRI or SNRI, the FDA warning is not necessarily warranted. ${ }^{61-63}$

In terms of hypersensitivity to sumatriptan-naproxen, patients should not take this medication if they are allergic to either one of its components. For NSAIDs, agents of the same class tend to show higher cross-sensitivity. For naproxen, other propionic acid based NSAIDs include: fenoprofen $\left(\mathrm{Nalfon}^{\circledR}\right)$, flurbiprofen $\left(\right.$ Ocufen $\left.^{\circledR}\right)$, ibuprofen
(Addaprin; Advil $^{\circledR} ;$ Caldolor $^{\mathrm{TM}}$; Genpril ${ }^{\circledR}$; I-Prin; Ibu-200; $\mathrm{Ibu}^{\circledR} ;$ Midol $^{\circledR} ;$ Motrin $^{\circledR} ;$ NeoProfen $^{\circledR} ;$ Proprinal; Ultraprin), ketoprofen (Apo-Keto ${ }^{\circledR}$; Novo-Keto; Nu-Ketoprofen; Oruvail $^{\circledR}$; Rhodis ${ }^{\mathrm{TM}}$ ) and oxaprozin $\left(\right.$ Daypro $\left.^{\circledR}\right) .{ }^{64}$ Therefore, patients with known sensitivity to any of these medications should be cautious in their use of sumatriptannaproxen. On the other hand, true allergic reaction to triptans is extremely rare, and cross-reactivity among triptans is unknown. Some triptans, including sumatriptan, contain a sulfonamide structure. However cross-reactivity between antibiotic sulfonamides and nonantibiotic sulfonamides does not occur, or at most has an extremely low potential. ${ }^{65-67}$

The most common side effects of triptans, including sumatriptan-naproxen, are chest and neck pressure, tingling, paresthesia, flushing, dizziness and sedation. ${ }^{40,54,55}$ As with any of the analgesics, one should always be aware of the risk for medication overuse headache with frequent use of triptans. ${ }^{68}$

A major main concern when using triptans in general, including sumatriptan and hence sumatriptan-naproxen, is the cardiovascular safety. ${ }^{69} \mathrm{~A}$ review of clinical data about the cardiovascular tolerability and safety of triptans indicates that most chest symptoms are nonischemic and nonserious. Serious cardiovascular events do occur rarely however, but it is in patients with multiple cardiovascular risk factors or known cardiovascular disease. Therefore, triptan should be considered safe in patients with no or low cardiovascular risk. ${ }^{70}$ As for the naproxen component, it does not seem to alter cardiovascular risk, despite the general recommendation that NSAIDs and selective COX-2 inhibitors may increase cardiovascular complications. ${ }^{71-74}$

As for pregnancy risk, both naproxen and sumatriptan are classified as category $\mathrm{C}$, that is "animal reproduction studies have shown an adverse effect on the fetus and there are no adequate and well-controlled studies in humans, but potential benefits may warrant use of the drug in pregnant women despite potential risks". ${ }^{13,40,54,55}$ However, there has not been an association between naproxen and fetal defects. ${ }^{13}$ With sumatriptan, there is lack of adequate studies to assess the fetal risk, with some animal studies demonstrating a lethal effect on the embryo, while others demonstrating no such risk. ${ }^{40,54,55}$ There is an established pregnancy registry for sumatriptan (800-336-2176), and many experts in embryo-toxicity propagate it to be relatively safe to use sumatriptan in pregnant migraine patients, due to the high number of observed pregnancies without any severe malformations or other teratogenic effect. ${ }^{75,76}$ 
Both naproxen and sumatriptan are excreted in breast milk, ${ }^{40,41,54-57,59,77}$ but the American Academy of Pediatrics considers them to be breastfeeding "compatible. ${ }^{77 \text { " }}$

\section{Overview of pharmacokinetics of sumatriptan-naproxen}

Though sumatriptan-naproxen shares a similar pharmacologic profile with its individual components, its pharmacokinetics are different.

Maximal concentration $\left(\mathrm{C}_{\max }\right)$ for sumatriptan following administration of sumatriptan-naproxen occurs at approximately 1 hour (median, range 0.3 to 4.0 hours). $\mathrm{C}_{\max }$ for naproxen following administration of sumatriptan-naproxen occurs at approximately 5 hours (median, range 0.3 to 12 hours). The mean $\mathrm{C}_{\max }$ for sumatriptan when given as sumatriptan-naproxen is similar to that of sumatriptan when given as a $100 \mathrm{mg}$ tablet alone. ${ }^{78}$ By contrast, naproxen administered alone reaches peak serum concentration in 1 to 4 hours. ${ }^{13,21,79}$ This is approximately $36 \%$ lower than with the combination tablet; thus, the combination tablet seems to delay the time to maximum concentration of the naproxen. ${ }^{78}$

In the combination tablet, the sumatriptan half-life is approximately 2 hours ( $15 \%$ to $43 \% \mathrm{CV})$ and the naproxen half-life is approximately 19 hours ( $13 \%$ to $15 \% \mathrm{CV})$. The median sumatriptan time to maximum concentration $\left(\mathrm{T}_{\max }\right)$ is only slightly different (1 hour for sumatriptan-naproxen and 1.5 hours for sumatriptan $100 \mathrm{mg}$ tablets), and the $\mathrm{T}_{\max }$ occurs approximately 4 hours later from sumatriptan-naproxen than from the $550 \mathrm{mg}$ naproxen sodium tablets. The areas under the curve however for sumatriptan and for naproxen are similar for sumatriptan-naproxen compared to the individual tablets of its component. ${ }^{78}$

Naproxen is almost completely albumin bound in the serum with a volume of distribution of $0.16 \mathrm{~L} / \mathrm{kg}$. For the acute treatment of pain, it has a one hour onset of action. However, the onset of action of its anti-inflammatory effect is around 2 weeks, with a peak of action at 2-4 weeks. Its analgesic effect lasts up to 7 hours and its anti-inflammatory effect up to 12 hours. ${ }^{13,21,79}$ Sumatriptan's volume of distribution is $2.4 \mathrm{~L} / \mathrm{kg}$ and it is partly protein bound (14\% to $21 \%){ }^{34,40-43,54-57,80-104}$

Naproxen is metabolized in the liver and is a minor substrate of the CYP1A2 and CYP2C9 enzyme. Its metabolites are primarily eliminated in the urine $(95 \%)$, with a halflife elimination of up to 12 hours. Only a minor fraction is excreted in feces. ${ }^{13,14}$ On the other hand, $40 \%$ of the total dose of oral sumatriptan is excreted in feces and the remainder in urine. Urinary elimination consists of both the indole acetic metabolite as well as the unchanged drug. ${ }^{34,40-43,54-57,81,82,87,91-93,104-108}$
It is recommended that sumatriptan, sumatriptan-naproxen and all other triptans be administered at the onset of headache, or as soon as possible in the migraine attack, but not during the aura symptoms that occur at the beginning of an attack. If the headache persists, then a second dose may be administered at 2 hours, with a maximum of 2 doses within a 24-hour period. This is true for all formulations and all dosages. It is not recommended to combine different triptans. ${ }^{34,36,40,41,54-57,81,84,85,89,107,109-111}$

There are no specific dose adjustments required in the elderly. ${ }^{13,54,55,91}$ However, the free plasma level of naproxen is higher in geriatrics than in younger adults, and the elderly are at increased risk for adverse effects even at low doses. Therefore one might therefore need to start with lower dosages. ${ }^{13,14}$

\section{Sumatriptan-naproxen efficacy studies}

Both concomitant administration of sumatriptan and naproxen and sumatriptan-naproxen fixed combination tablet (Treximet $^{\circledR}$ ) have been shown to have superior efficacy to either one of the two medicines used alone, with a synergistic effect being noted. ${ }^{12}$ Summary of the two seminal studies that led to the approval of sumatriptan-naproxen by the FDA is shown (Table 1). ${ }^{38}$

Similar to sumatriptan, sumatriptan-naproxen addresses both the headache and the nonheadache symptoms of migraine, namely photophobia, phonophobia and nausea. ${ }^{38}$

Sumatriptan-naproxen shows consistency of response in other study designs too. In two cross over studies, sumatriptan-naproxen combination shows greater response than placebo in terms of pain freedom 2 -hour postdose $(52 \%$ versus $25 \%$ in study 1 and $50 \%$ versus $20 \%$ in study 2 ), in sustained pain freedom at 24 hours (37\% versus $17 \%$ in study 1 and $34 \%$ versus $12 \%$ in study 2 ), and in migraine freedom at 2 hours and 4 hours postdose (no pain, nausea, vomiting, photophobia, phonophobia, and no use of rescue medications). Adverse events were 9\% (versus 7\% in the placebo group) in study 1 and $13 \%$ (versus $9 \%$ in the placebo group) in study $2 .{ }^{113}$ More importantly, even in migraineurs who do not respond to sumatriptan monotherapy, sumatriptan-naproxen demonstrates greater efficacy than placebo in aborting migraine attacks, both in terms of pain as well as photophobia and phonophobia. In two studies by Mathew and colleagues a 2 hour pain free rate with sumatriptan-naproxen was $40 \%$ and $44 \%$ versus $17 \%$ and $14 \%$ for placebo, and sustained pain freedom rates at 2 to 24 hours with sumatriptan-naproxen were $26 \%$ and $37 \%$ versus with $8 \%$ and $8 \%$ for placebo. ${ }^{114}$ 
Table I Percentage of patients with 2-hour pain relief and sustained pain relief following treatment*38

\begin{tabular}{|c|c|c|c|c|}
\hline & Sumatriptan-naproxen & Sumatriptan 85 mg & Naproxen sodium 500 mg & Placebo \\
\hline \multicolumn{5}{|l|}{ 2-hour pain relief } \\
\hline \multirow[t]{2}{*}{ Study I (all patients) } & $65 \%^{\dagger}$ & $55 \%$ & $44 \%$ & $28 \%$ \\
\hline & $\mathrm{n}=364$ & $\mathrm{n}=36 \mathrm{I}$ & $\mathrm{n}=356$ & $\mathrm{n}=360$ \\
\hline \multirow[t]{2}{*}{ Study 2 (all patients) } & $57 \%^{+}$ & $50 \%$ & $43 \%$ & $29 \%$ \\
\hline & $\mathrm{n}=362$ & $\mathrm{n}=362$ & $\mathrm{n}=364$ & $\mathrm{n}=382$ \\
\hline \multicolumn{5}{|c|}{ Sustained pain relief ( 2 to 24 hours) } \\
\hline \multirow[t]{2}{*}{ Study I } & $25 \%{ }^{\ddagger}$ & $16 \%$ & $10 \%$ & $8 \%$ \\
\hline & $\mathrm{n}=364$ & $\mathrm{n}=36 \mathrm{I}$ & $\mathrm{n}=356$ & $\mathrm{n}=360$ \\
\hline \multirow[t]{2}{*}{ Study 2} & $23 \%{ }^{\ddagger}$ & $14 \%$ & $10 \%$ & $7 \%$ \\
\hline & $\mathrm{n}=362$ & $\mathrm{n}=362$ & $\mathrm{n}=364$ & $\mathrm{n}=382$ \\
\hline
\end{tabular}

*P values provided only for prespecified comparisons.

${ }^{\dagger} P<0.05$ versus placebo and sumatriptan.

${ }^{\ddagger} P<0.01$ versus placebo, sumatriptan, and naproxen sodium.

Sumatriptan-naproxen is not only effective against the traditional symptoms of migraine (pain, nausea, vomiting, photophobia, phonophobia), but also the nontraditional migraine symptoms (neck pain/discomfort, sinus pain/ pressure). In 2 identical, randomized, double-blind, placebocontrolled trials that enrolled 576 and 535 migraineurs respectively, with similar incidence of different migraine symptoms between the treated and the placebo group, after early treatment the nontraditional symptoms occurrence 2 hours and 4 hours post-treatment were significantly lower as compared to placebo (Table 2). ${ }^{115}$

Sumatriptan-naproxen also showed superior efficacy and tolerability vs placebo in the treatment of menstrual migraine and dysmenorrhea in 2 replicate studies. This effect was seen for 2-hour pain response, 2 hour to 48 hours sustained pain response, use of rescue medications and in nonmigraine menstrual symptoms (bloating, tiredness, irritability, overall nonmigraine pain intensity), except for menstrual pain. ${ }^{116}$

Despite the advantage of sumatriptan-naproxen, there is a relative lack of data comparing it directly to its components. The improved efficacy in clinical trials over sumatriptan is in the range of only $5 \%$ to $10 \%$. In addition, the efficacy of sumatriptan in the sumatriptan-naproxen studies is lower than was previously reported. ${ }^{117}$ One must therefore weigh this advantage against the significantly higher price of sumatriptan-naproxen compared to its components, where sumatriptan-naproxen costs around $\$ 22.00$ per dose versus $\$ 6.60$ per dose for generic sumatriptan $100 \mathrm{mg}$ and generic naproxen $500 \mathrm{mg} .{ }^{118}$

\section{Patient focused perspectives such as quality of life, patient satisfaction/ acceptability, adherence and uptake}

A recent study identified 5 factors that predict patient adherence to triptan therapy. ${ }^{119}$ In decreasing order of importance, these include: a) Confidence in the triptan's ability to abort the migraine attack; b) The perceived importance of the triptan in the treatment of the migraine attack; c) Satisfaction with the triptan; d) Speed of onset of triptan analgesic effect; e) Time to disability resolution and patient's return to normal activities. A negative predictive factor was the occurrence of side effects. Migraine severity was not a predictive factor of adherence to therapy.

Sumatriptan-naproxen, with its consistent efficacy response and favorable side effect profile ${ }^{113}$ increases the likelihood of adherence by patients. Over a 12-month period, it demonstrated consistent efficacy with low recurrence rates,

Table 2 Occurrence of nontraditional migraine symptoms 2-hour and 4-hour following treatment ${ }^{115}$

\begin{tabular}{|c|c|c|c|c|}
\hline & \multicolumn{2}{|l|}{ Study I } & \multicolumn{2}{|l|}{ Study 2} \\
\hline & Sumatriptan-naproxen & Placebo & Sumatriptan-naproxen & Placebo \\
\hline Neck pain/discomfort 2-hour postdose & $35 \%$ & $44 \%$ & $28 \%$ & $54 \%$ \\
\hline Neck pain/discomfort 4-hour postdose & $19 \%$ & $46 \%$ & $19 \%$ & $46 \%$ \\
\hline Sinus pressure/pain 2-hour postdose & $19 \%$ & $35 \%$ & $23 \%$ & $38 \%$ \\
\hline Sinus pressure/pain 4-hour postdose & $10 \%$ & $30 \%$ & $15 \%$ & $32 \%$ \\
\hline
\end{tabular}

All results significant at 0.001 or less. 
and tolerability with low side effect rates and improved quality of life scores, again resulting in improved patient satisfaction and hence improved patient compliance. ${ }^{120}$

\section{Conclusions and place in therapy}

Sumatriptan-naproxen sodium fixed combination tablet $\left(\right.$ Treximet $^{\circledR}$ ) theoretically will abort migraine in its initial stages at the trigeminal ganglion and will prevent the slow central sensitization.

The combination is modestly superior to sumatriptan or naproxen alone, as shown in the 2 seminal studies; ${ }^{38}$ however the $50 \%$ to $55 \%$ 2-hour pain relief and $14 \%$ to $16 \% 2$ hour pain freedom for sumatriptan are lower than the efficacy reported for sumatriptan in the triptan meta-analysis by Ferrari and colleagues. ${ }^{117}$

Sumatriptan-naproxen may restore responsiveness in subjects that have become tachyphylactic to triptans, and has a favorable side-effect profile, making it an effective and well-tolerated migraine abortive treatment, but it is far from being the gold standard treatment. Research to develop additional medication is still needed.

\section{Disclosures}

The authors report no conflicts of interest in this work.

\section{References}

1. Rasmussen BK. Epidemiology of headache. Cephalalgia. 2001; 21(7):774-777.

2. Schwartz BS, Stewart WF, Simon D, Lipton RB. Epidemiology of tension-type headache. JAMA. 1998;279(5):381-383.

3. Lipton RB, Stewart WF. Migraine in the United States: a review of epidemiology and health care use. Neurology. 1993;43(6 Supplement 3): S6-S10.

4. Launer LJ, Terwindt GM, Ferrari MD. The prevalence and characteristics of migraine in a population-based cohort: the GEM study. Neurology. 1999;53(3):537-542.

5. Lipton, et al. Headaches and face pain as a manisfestation of Munchausen Syndrome. Headache. 1999;39(1):45-50.

6. Stewart WF, Lipton RB, Simon D. Work-related disability: results from the American migraine study. Cephalalgia. 1996;16(4):231-238.

7. Osterhaus JT, Gutterman DL, Plachetka JR. Healthcare resource and lost labour costs of migraine headache in the US. Pharmacoeconomics. 1992;2(1):67-76.

8. Clouse JC, Osterhaus JT. Healthcare resource use and costs associated with migraine in a managed healthcare setting. Ann Pharmacother. 1994;28(5):659-664.

9. Lipton RB, Bigal ME, Diamond M, Freitag F, Reed ML, Stewart WF; AMPP Advisory Group. Migraine prevalence, disease burden, and the need for preventive therapy. Neurology. 2007;68(5):343-349.

10. Rapoport AM. Acute treatment of headache. J Headache Pain. 2006;7(5):355-359. Epub 2006 Oct 27.

11. Evers S, Afra J, Frese A, et al. EFNS guideline on the drug treatment of migraine - revised report of an EFNS task force. Eur $J$ of Neurol. 2009; 16(9):968-981

12. Lexi-Comp Online [homepage on the Internet]. Hudson, $\mathrm{OH}$ : Lexi-Comp, Inc.; c2008-09 [cited 2009 Aug 27]. Available from: http://online.lexi.com/crlsql/servlet/crlonline?siteid=721.
13. Roche. EC-Naprosyn ${ }^{\circledR}$ (naproxen) delayed-release tablets, Naprosyn ${ }^{\circledR}$ (naproxen) tablets, Anaprox ${ }^{\circledR} /$ Anaprox $^{\circledR}$ DS (naproxen sodium) tablets, and Naprosyn ${ }^{\circledR}$ (naproxen) suspension prescribing information. Nutley, NJ; 2006.

14. Elan. Naprelan ${ }^{\circledR}$ (naproxen sodium) controlled-release tablets prescribing information (dated 2000 Mar) In: Physician's desk reference. 56th ed. Montvale, NJ: Medical Economics Company, Inc; 2002. p. 1293-1295.

15. Hawkey CJ. COX-2 inhibitors. Lancet. 1999;353:307-314.

16. Kurumbail RG, Stevens AM, Gierse JK, et al. Structural basis for selective inhibition of cyclooxygenase-2 by anti-inflammatory agents. Nature. 1996;384:644-648.

17. Riendeau D, Charleson S, Cromlish W, et al. Comparison of the cyclooxygenase-1 inhibitory properties of nonsteroidal antiinflammatory drugs (NSAIDs) and selective COX-2 inhibitors, using sensitive microsomal and platelet assays. Can J Physiol Pharmacol. 1997;75:1088-1095.

18. DeWitt DL, Bhattacharyya D, Lecomte M, et al. The differential susceptibility of prostaglandin endoperoxide $\mathrm{H}$ synthases- 1 and -2 to nonsteroidal anti-inflammatory drugs: aspirin derivatives as selective inhibitors. Med Chem Res. 1995;5:325-343.

19. Cryer B, Dubois A. The advent of highly selective inhibitors of cyclooxygenase - a review. Prostaglandins and Other Lipid Mediators. 1998;56:341-361.

20. Simon LS. Role and regulation of cyclooxygenase-2 during inflammation. Am J Med. 1999;106(Suppl 5B):37S-42S.

21. Ansell BM, Hanna DB, Stoppard M. Naproxen absorption in children. Curr Med Res Opin. 1975;3:46-50.

22. Moran H, Hanna DB, Ansell BM, et al. Naproxen in juvenile chronic polyarthritis. Ann Rheum Dis. 1979;38:152-154.

23. Makela AL. Naproxen in the treatment of juvenile rheumatoid arthritis. Scand J Rheumatol. 1977;6:193-205.

24. Nicholls A, Hazleman B, Todd RM, et al. Long-term evaluation of naproxen suspension in juvenile chronic arthritis. Curr Med Res Opin. 1982;8:204-207.

25. Kvien TK, Hoyeraal HM, Sandstad B. Naproxen and acetylsalicylic acid in the treatment of pauciarticular and polyarticular juvenile rheumatoid arthritis: assessment of tolerance and efficacy in a singlecentre 24-week double-blind parallel study. Scand J Rheumatol. 1984;13:342-350.

26. Williams PL, Ansell BM, Bell A, et al. Multicentre study of piroxicam versus naproxen in juvenile chronic arthritis, with special reference to problem areas in clinical trials of nonsteroidal anti-inflammatory drugs in childhood. Br J Rheumatol. 1986;25:67-71.

27. Johnson ES, Ratcliffe DM, Wilkinson M. Naproxen sodium in the treatment of migraine. Cephalalgia. 1985;5:5-10.

28. Snow V, Weiss K, Wall EM, et al. Pharmacologic Management of Acute Attacks of Migraine and Prevention of Migraine Headache. Ann Intern Med. 2002;137(10):840-849.

29. Matchar DB, Young WB, Rosenberg JH, et al. Evidence-based guidelines for migraine headache in the primary care setting: pharmacological management of acute attacks. St. Paul, MN: American Academy of Neurology; 2001. Available from: http://www.aan.com.

30. Bayer HealthCare. Aleve ${ }^{\circledR}$ (naproxen sodium) tablet labeling. Morristown, NJ; 2006.

31. Ramadan NM, Silberstein SD, Freitag FG, et al. Evidence-based guidelines for migraine headache in the primary care setting: pharmacological management for prevention of migraine. St. Paul, MN: American Academy of Neurology; 2001. Available from: http://www.aan.com.

32. Gold, Harriott. Serotonin type 1D receptors (5HTR) are differentially distributed in nerve fibers innervating craniofacial tissues. Cephalalgia. 2008;28:933-944.

33. Silberstein SD, Freitag FG, Bigal ME. Migraine treatment. In: Silberstein SD, Lipton RB, Dodick DW, editors. Wolff's headache and other head pain. 8th ed. New York: Oxford University Press; 2008. p. 177-292.

34. McGuigan MA. Ergot Alkaloids. Clin Toxicol Rev. 1984;6:1-2. 
35. Hsu VD. Sumatriptan: a new drug for vascular headache. Clin Pharm. 1992;11:919-929.

36. Silberstein SD. Practice parameter: Evidence-based guidelines for migraine headache (an evidence-based review): Report of the Quality Standards Subcommittee of the American Academy of Neurology. Neurology. 2000;55:538-547.

37. Burstein R, Jakubowski M. Analgesic triptan action in an animal model of intracranial pain: a race against the development of central sensitization. Ann Neurol. 2004;55(1):27-36.

38. Burstein R, Collins B, Jakubowski M. Defeating migraine pain with triptans: a race against the development of cutaneous allodynia. Ann Neurol. 2004;55(1):19-26.

39. Brandes JL, Kudrow D, Stark SR, et al. Sumatriptan-naproxen for acute treatment of migraine: a randomized trial. JAMA. 2007;297(13):1443-1454.

40. GlaxoSmithKline. Imitrex ${ }^{\circledR}$ (sumatriptan succinate) tablets prescribing information. Research Triangle Park, NC; 2001.

41. GlaxoSmithKline. Imitrex ${ }^{\circledR}$ (sumatriptan succinate) tablets prescribing information. Research Triangle Park, NC; 2006.

42. Lacey LF, Fowler PA. The clinical pharmacology of sumatriptan. Cephalalgia. 1993;13(Suppl 13):156.

43. Plosker GL, McTavish D. Sumatriptan: a reappraisal of its pharmacology and therapeutic efficacy in the acute treatment of migraine and cluster headache. Drugs. 1994;47:622-651.

44. Food and Drug Administration. Analysis and recommendations for agency action regarding non-steroidal anti-inflammatory drugs and cardiovascular risk. 2005 Apr 6 [cited 2009 Aug 27]. Available from: http://www.fda.gov.

45. Sanak M, Pierzchalska M, Bazan-Socha S, et al. Enhanced Expression of the Leukotriene C(4) Synthase Due to Overactive Transcription of an Allelic Variant Associated With Aspirin-Intolerant Asthma. Am J Respir Cell Mol Biol. 2000;23(3):290-296.

46. Kawagishi Y, Mita H, Taniguchi M, et al. Leukotriene C4 Synthase Promoter Polymorphism in Japanese Patients With Aspirin-Induced Asthma. J Allergy Clin Immunol. 2002;109(6):936-942.

47. Pope JE, Anderson JJ, Felson DT. A meta-analysis of the effects of nonsteroidal anti-inflammatory drugs on blood pressure. Arch Intern Med. 1993;153:477-484.

48. Steinhubl SR. The use of anti-inflammatory analgesics in the patient with cardiovascular disease: what a pain. $J$ Am Coll Cardiol. 2005;45(8):1302-1303.

49. Food and Drug Administration. New information for healthcare professionals: Concomitant use of ibuprofen and aspirin. $2006 \mathrm{Sep}$ [cited 2009 Aug 27]. Available from: http://www.fda.gov.

50. Food and Drug Administration. Concomitant use of ibuprofen and aspirin: potential for attenuation of the antiplatelet effect of aspirin [science paper]. 2006. Available from: http://www.fda.gov.

51. Capone ML, Sciulli MG, Tacconelli S, et al. Pharmacodynamic interaction of naproxen with low-dose aspirin in healthy subjects. $J \mathrm{Am}$ Coll Cardiol. 2005;45:1295-1301.

52. Food and Drug Administration. Labeling revisions for NSAIDs. FDA Drug Bull. 1989;19:3-4.

53. Merck \& Co., Inc. Dolobid ${ }^{\circledR}$ (diflunisal) tablets prescribing information. Whitehouse Station, NJ; 2006 Feb.

54. Glaxo Wellcome. Imitrex ${ }^{\circledR}$ (sumatriptan succinate) injection prescribing information. Research Triangle Park, NC; 2001 Mar.

55. Glaxo Wellcome. Imitrex ${ }^{\circledR}$ (sumatriptan) nasal spray prescribing information. Research Triangle Park, NC; 2001 Mar.

56. McEvoy GK, editor. AHFS drug information: naproxen. Bethesda, MD: American Society of Health-System Pharmacists; 2003. p. 1986-1992.

57. GlaxoSmithKline. Imitrex ${ }^{\circledR}$ (sumatriptan succinate) injection prescribing information. Research Triangle Park, NC; 2006 Jun.

58. Food and Drug Administration. Combined Use of 5-Hydroxytryptamine Receptor Agonists (Triptans), Selective Serotonin Reuptake Inhibitors (SSRIs) or Selective Serotonin/Norepinephrine Reuptake Inhibitors (SNRIs) May Result in Life-threatening Serotonin Syndrome. $2006 \mathrm{Jul}$ 19 [updated 2009 Jul 1; cited 2009 Aug 27]. Available from: http://www. fda.gov/Drugs/DrugSafety/PublicHealthAdvisories/ucm124349.htm.
59. GlaxoSmithKline. Imitrex ${ }^{\circledR}$ (sumatriptan) nasal spray prescribing information. Research Triangle Park, NC; 2006 Jun.

60. Isbister GK, Buckley NA. The pathophysiology of serotonin toxicity in animals and humans: implications for diagnosis and treatment. Clin Neuropharmacol. 2005;28:205-214.

61. MedGenMed, Evans RW. The FDA alert on serotonin syndrome with combined use of SSRIs or SNRIs and Triptans: an analysis of the 29 case reports. 2007;9(3):48.

62. Shapiro RE, Tepper SJ. The Serotonin Syndrome, Triptans, and the potential for drug-drug interactions. Headache. 2007;47(2): 266-269.

63. Wenzel RG, Tepper S, Korab WE, Freitag F. Serotonin syndrome risks when combining SSRI/SNRI drugs and triptans: is the FDA's alert warranted? Ann Pharmacother. 2008;42(11):1692-1696. Epub 2008 Oct 28 .

64. Lexi-Comp Online [homepage on the Internet]. Hudson, $\mathrm{OH}$ : Lexi-Comp, Inc.; c2008-09 [cited 2009 Jul 28]. Available from: http:// online.lexi.com.webproxy.ouhsc.edu/crlsq1/servlet/crlonline? $\mathrm{a}=\mathrm{doc} \& \mathrm{~b}$ $\mathrm{i}=3 \& \mathrm{id}=3725$.

65. Block JH, Brackett CC, Singh H. Likelihood and mechanisms of cross-allergenicity between sulfonamide antibiotics and other drugs containing a sulfonamide functional group. Pharmacotherapy. 2004;24(7):856-870.

66. Slatore CG, Tilles SA. Sulfonamide hypersensitivity. Immunol Allergy Clinic North Am. 2004;24(3):477-490, vii.

67. Baeza ML, De Barrio M, Herro T, Tornero. Cross-reactivity among p-amino group compounds in sulfonamide fixed drug eruption: diagnostic value of patch testing. Contact Dermititis. 2004;51(2):57-62.

68. Couch JR, Lenaerts ME. Medication overuse headache. Minerva Med. 2007;98:221-231.

69. Young WB, Mannix L, Adelman JU, et al. Cardiac risk factors and the use of triptans: a survey study. Headache. 2000;40:587-591.

70. Dodick D, Lipton RB, Martin V, et al; Triptan Cardiovascular Safety Expert Panel. Consensus statement: cardiovascular safety profile of triptans (5-HT agonists) in the acute treatment of migraine. Headache. 2004;44(5):414-425.

71. McGettigan P, Henry D. Cardiovascular risk and inhibition of cyclooxygenase: a systematic review of observational studies of selective and nonselective inhibitors of cyclooxygenase 2. JAMA. 2006;296:1633-1644.

72. Kearney PM, Baigent C, Godwin J, et al. Do selective cyclo-oxygenase-2 inhibitors and traditional non-steroidal anti-inflammatory drugs increase the risk of atherothrombosis? Meta-analysis of randomized trials. $B M J$. 2006;332:1302-1305.

73. Graham DJ. COX-2 inhibitors, other NSAIDs, and cardiovascular risk; the seduction of common sense. JAMA. 2006;296:1653-1656.

74. Chou R, Helfand M, Peterson K, et al; for the Oregon evidence-based practice center under contract no. 290-02-0024. Comparative effectiveness and safety of analgesics for osteoarthritis. Comparative effectiveness review no. 4. Rockville, MD: Agency for Healthcare Research and Quality. 2006 Sep. Available from: http://www.effectivehealthcare. ahrq.gov/synthesize/reports/final.cfm.

75. Fox AW, Spierings EL. Sumatriptan and pregnancy outcome. Headache. 2000;40(10):860-861.

76. Loder E. Safety of sumatriptan in pregnancy: a review of the data so far. CNS Drugs. 2003;17(1):1-7.

77. American Academy of Pediatrics Committee on Drugs. The Transfer of Drugs and Other Chemicals Into Human Milk. Pediatrics. 2001;108(3):776-789.

78. GlaxoSmithKline. Treximet ${ }^{\mathrm{TM}}$ (sumatriptan and naproxen sodium) tablets prescribing information. Research Triangle Park, NC; 2008 Aug.

79. Kauffmann RE, Bolliger RO, Wan SH, et al. Pharmacokinetics and metabolism of naproxen in children. Dev Pharmacol Ther. 1982;5: $143-150$.

80. Akpunonu BE, Mutgi AB, Federman DJ, et al. Subcutaneous sumatriptan for treatment of acute migraine in patients admitted to the emergency department: a multicenter study. Ann Emerg Med. 1995;25:464-469. 
81. Bateman DN. Sumatriptan. Lancet. 1993;341:221-224.

82. Busch MA, Plachetka JR, Donn KH. Evaluation of the pharmacokinetics and safety of ascending single oral doses of GR43175 administered to healthy male volunteers. Cephalalgia. 1989;9(Suppl 10): 414-415.

83. Cady RK, Dexter J, Sargent JD, et al. Efficacy of subcutaneous sumatriptan in repeated episodes of migraine. Neurology. 1993;43: 1363-1368.

84. Cady RK, Rubino J, Crummett D, et al. Oral sumatriptan in the treatment of recurrent headache. Arch Fam Med. 1994;3:766-772.

85. Cady RK, Wendt JK, Kirchner JR, et al. Treatment of acute migraine with subcutaneous sumatriptan. JAMA. 1991;265:2831-2835.

86. Cutler NR, Hussey EK, Sramek JJ, et al. Pharmacokinetics (PK) of oral sumatriptan in migraine patients during an attack and while pain free. Biol Psych. 1992;31:180A.

87. Dixon CM, Saynor DA, Andrew PD, et al. Disposition of sumatriptan in laboratory animals and humans. Drug Metabol Disp. 1993;21:761-769.

88. Ekbom K, Monstad I, Prusinski A, et al. Subcutaneous sumatriptan in the acute treatment of cluster headache: a dose comparison study. Acta Neurol Scand. 1993;88:63-69.

89. Ferrari MD and the Subcutaneous Sumatriptan International Study Group. Treatment of migraine attacks with sumatriptan. N Engl J Med. 1991;325:316-321.

90. Ferrari MD, Saxena PR. Clinical and experimental effects of sumatriptan in humans. Trends Pharmacol Sci. 1993;14:129-133.

91. Fowler PA, Lacey LF, Thomas M, et al. The clinical pharmacology, pharmacokinetics, and metabolism of sumatriptan. Eur Neurol. 1991;31:291-294.

92. Fowler PA, Thomas M, Lacey LF, et al. Early studies with the novel 5-HT1-like agonist GR43175 in healthy volunteers. Cephalalgia. 1989;9(Suppl 9):57-62.

93. Gutterman DL, Plachetka JR, Donn K, et al. Evaluation of the safety and pharmacokinetic properties of single subcutaneous doses of GR43175C in healthy, adult, male volunteers. Cephalalgia. 1989; 9(Suppl 10):412-413.

94. Hardebo JE. Subcutaneous sumatriptan in cluster headache: a time study of the effect on pain and autonomic symptoms. Headache. 1993;33:18-21.

95. Lacey LF, Hussey EK, Fowler PA. Single dose pharmacokinetics of sumatriptan in healthy volunteers. Eur J Clin Pharmacol. 1995;47: 543-548.

96. Posner JB. Disorders of sensation: headache and other pain. In: Wyngaarden JB, Smith LH Jr, Bennett JC, editors. Cecil textbook of medicine. 19th ed. Philadelphia: WB Saunders Company; 1992. p. 2116-2124.

97. Rederich G, Rapoport A, Cutler N, et al. Oral sumatriptan for the long-term treatment of migraine: clinical findings. Neurology. 1995;45(Suppl 7):S15-S20.

98. Salonen R, Ashford E, Dahlöf C, et al. Intranasal sumatriptan for the acute treatment of migraine. J Neurol. 1994;241:463-469.

99. Scott AK. Sumatriptan: clinical pharmacokinetics. Clin Pharmacokinet. 1994;27:337-344.

100. Tansey MJB, Pilgrim AJ, Lloyd K. Sumatriptan in the acute treatment of migraine. J Neurol Sci. 1993;114:109-116.

101. The Finnish Sumatriptan Group and the Cardiovascular Clinical Research Group. A placebo-controlled study of intranasal sumatriptan for the acute treatment of migraine. Eur Neurol. 1991;31:332-338.
102. The Oral Sumatriptan International Multiple-Dose Study Group. Evaluation of a multiple-dose regimen of oral sumatriptan for the acute treatment of migraine. Eur Neurol. 1991;31:306-313.

103. The Sumatriptan Cluster Headache Study Group. Treatment of acute cluster headache with sumatriptan. $N$ Engl J Med. 1991;325:322-326.

104. Warner PE, Brouwer KLR, Hussey EK, et al. Sumatriptan absorption from different regions of the human gastrointestinal tract. Pharm Res. $1995 ; 12: 138-143$.

105. Anon. Sumatriptan: a new approach to migraine. Drug Ther Bull. 1992;30:85-87.

106. Dixon CM, Park GR, Tarbit MH. Characterization of the enzyme responsible for the metabolism of sumatriptan in human liver. Biochem Pharmacol. 1994:47:1253-1257.

107. Fullerton T, Gengo FM. Sumatriptan: a selective 5-hydroxytryptamine receptor agonist for the acute treatment of migraine. Ann Pharmacother. 1992;26:800-808.

108. Tfelt-Hansen P, Brand J, Dano P, et al. Early clinical experience with subcutaneous GR43175 in acute migraine: an overview. Cephalalgia. 1989;9(Suppl 9):73-77.

109. Anon. Sumatriptan for migraine. Med Lett Drugs Ther. 1992;34: 91-93.

110. Ferrari MD, Saxena PRS. Clinical effects and mechanism of action of sumatriptan in migraine. Clin Neurol Neurosurg. 1992;94(Suppl): S73-S77.

111. Russell MB, Holm-Thomsen OE, Nielsen MR, et al. A randomized double-blind placebo-controlled crossover study of subcutaneous sumatriptan in general practice. Cephalalgia. 1994;14:291-296.

112. Silberstein SD, Stark S, DeRossett SE, et al. Superior clinical benefits of a new single-tablet formulation of sumatriptan formulated with RT technology and naproxen sodium. Neurology. 2006;66(Suppl 2):A254.

113. Lipton RB, Dodick DW, Adelman JU, et al. Consistency of response to sumatriptan/naproxen sodium in a placebo-controlled, crossover study. Cephalalgia. 2009;29(2):188-193. Epub 2008 Sep 24.

114. Mathew NT, Landy S, Stark S, et al. Fixed-dose sumatriptan and naproxen in poor responders to triptans with a short half-life. Headache. 2009;49(7):971-982. Epub 2009 May 27.

115. Silberstein SD, Mannix LK, Goldstein J, et al. Multimechanistic (sumatriptan-naproxen) early intervention for the acute treatment of migraine. Neurology. 2008;71(2):114-121. Erratum in: Neurology. 2009;72(15):1369. Toso, Cynthia [added].

116. Mannix LK, Martin VT, Cady RK, et al. Combination treatment for menstrual migraine and dysmenorrhea using sumatriptan-naproxen: two randomized controlled trials. Obstet Gynecol. 2009;114(1): 106-113.

117. Ferrari MD, Roon KI, Lipton RB, Goadsby PJ. Oral triptans (serotonin 5-HT(1B/1D) agonists) in acute migraine treatment: a meta-analysis of 53 trials. Lancet. 2001;358(9294):1668-1675.

118. Lockwood AH. Multimechanistic (sumatriptan-naproxen) early intervention for the acute treatment of migraine. Neurology. 2008;72(15): 1368-1379.

119. Cady RK, Maizels M, Reeves DL, Levinson DM, Evans JK. Predictors of adherence to triptans: factors of sustained vs. lapsed users. Headache. 2009;49(3):386-394. Epub 2009 Feb 11.

120. Smith T, Blumenthal H, Diamond M, et al. Sumatriptan/Naproxen sodium for migraine: efficacy, health related quality of life, and satisfaction outcomes. Headache. 2007;47(2):189-198.

\section{Publish your work in this journal}

Drug Design, Development and Therapy is an international, peerreviewed open-access journal that spans the spectrum of drug design and development through to clinical applications. Clinical outcomes, patient safety, and programs for the development and effective, safe, and sustained use of medicines are a feature of the journal,

\section{Dovepress}

which has also been accepted for indexing on PubMed Central. The manuscript management system is completely online and includes a very quick and fair peer-review system, which is all easy to use. Visit http://www.dovepress.com/testimonials.php to read real quotes from published authors. 